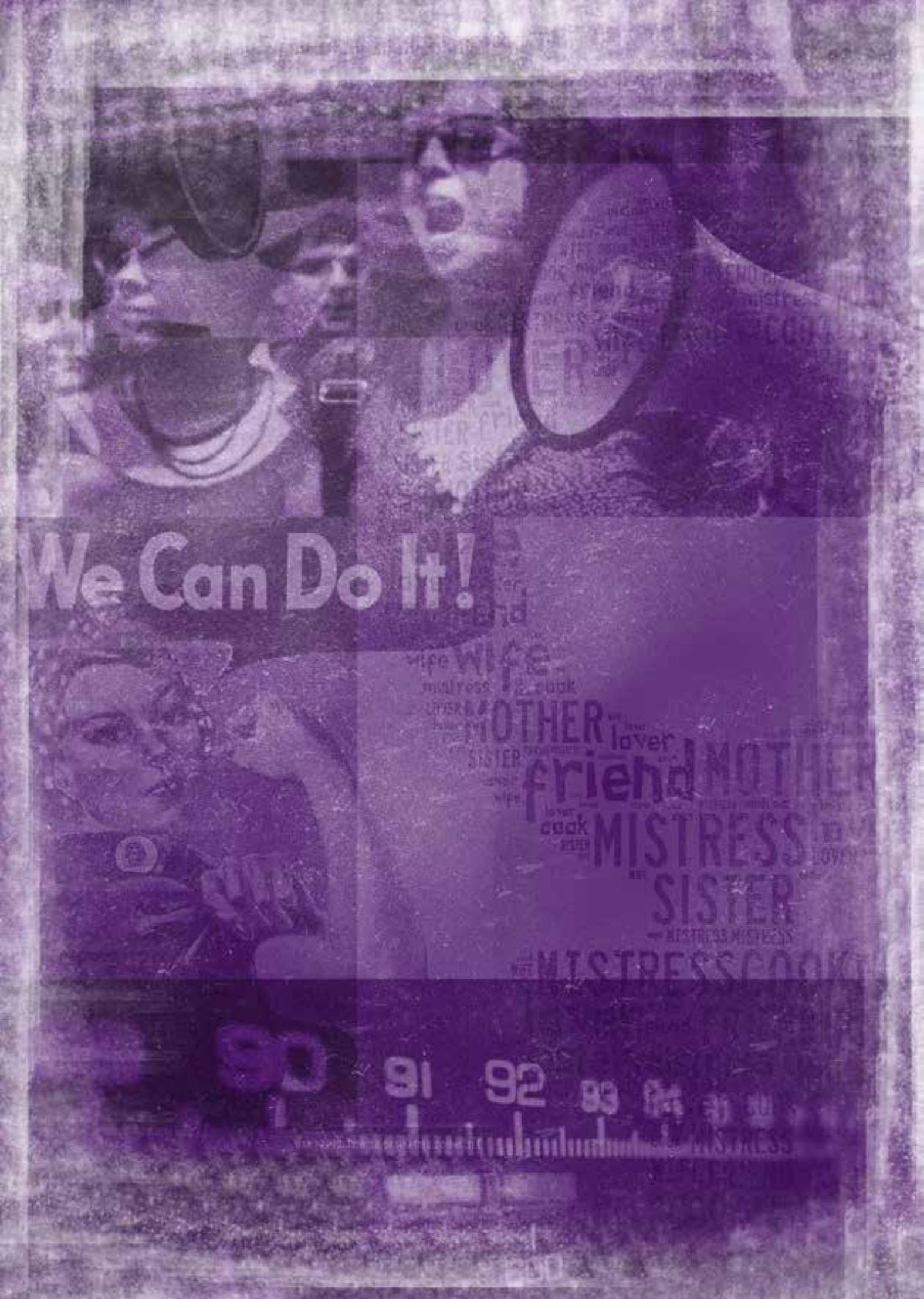




\title{
Ondas diferenciales para otras inadecuadas'. Feminismos, radios libre y discursos alternativos en la sociedad red: el caso del programa de radio Enredadas Mujeres
}

Differencial waves for inappropriated others. Feminism, free radios and alternative discourses in the network society: the case of the raio program Enredadas Mujeres

Dor: $10.15213 /$ redes.n11.p72

JÚLIA ARAÚJO MENDES

\begin{abstract}
This article is proposed as an approach to the problem of relations between social-political commitment, the practice of communication and technologies in the field of network society through a critical discourse analysis of a specific feminist radio program: Enredadas Mujeres, which is carried out from a free and self-organized radio in the maritime suburbs of Valencia (Spain). The text gives an overview on the concept of discourse and its relation with power, on how this relation has a leading role in the media scenario and on how communication is currently set by the network society phenomenon. Highlighting a critical approach to this phenomenon and recognizing its plasticity, the text presents some possibilities that have been developed to make communication without intermediaries. A fact that is largely encouraging minority and political resistance groups, of counter-information practices and feminist activism.

KEYWORDS: FEMINISMS, FREE RADIO, NETWORK SOCIETY, DISCOURSES, MICROPOLITICS

1. "Políticas diferenciales para otros inadecuados" es el título de la segunda parte del libro de Donna Haraway, Ciencia, cyborgs y mujeres (1995), en la que, entre otros temas, la autora aborda los conocimientos situados y el manifiesto para cyborgs. Aquí, me apropio y juego con dicho título, haciendo una alusión a las prácticas radiofónicas feministas.
\end{abstract}

REDES.COM N $\mathrm{N}^{\mathrm{O}} 11 \mid 73$ 


\section{RESUMEN}

El presente artículo es una propuesta de aproximación al problema de las relaciones entre compromiso político-social, la práctica de la comunicación y las tecnologías en el ámbito de la sociedad red, a través del análisis crítico del discurso de un programa de radio feminista en concreto: Enredadas Mujeres, que es llevado a cabo desde una radio libre y autogestionada de los Poblados Marítimos de la ciudad de Valencia. En el texto, se presenta un recorrido desde el concepto de discurso y su relación con el poder, de cómo esta relación es protagonista en el escenario de los medios de comunicación y de cómo la comunicación, actualmente, se enmarca en el fenómeno de la sociedad red. Remarcando una postura crítica hacia dicho fenómeno y reconociendo su plasticidad, se abordan las posibilidades que se han desarrollado de hacer comunicación sin intermediarios. Un hecho que viene favoreciendo, en gran medida, a colectivos minoritarios y de resistencia política, de contrainformación y feministas.

PALABRAS CLAVE: FEMINISMOS, RADIO LIBRE, SOCIEDAD RED, DISCURSOS, MICROPOLÍTICAS

\section{INTRODUCCIÓN}

Dentro de los cambios promovidos por las nuevas tecnologías de la información y de la comunicación, el concepto de radio también ganó otra dimensión, sobre todo la forma de hacer radio, el qué comunicar y el por qué. La transmisión en línea de las radios y el advenimiento de los podcasts posibilitó una mayor apertura del espacio radiofónico, hecho que ha favorecido los colectivos de radios libres y autogestionadas.

En diversas radios libres, grupos de mujeres optan por promover un modelo de contrainformación desde los feminismos, a través de la deconstrucción del discurso heteropatriarcal, de la difusión y creación de discursos alternativos y de la autogestión de sus voces. El producto de esos procesos es la producción de programas de radio que son emitidos por antena y también en línea y que, luego, se convierten en podcasts, a disposición de toda la Red.

No obstante, cabe preguntarse ¿qué entendemos por discursos alternativos? Siendo el ámbito de las radios libres entornos marginados y teniendo el discurso anti-heteropatriarcal un cuerpo teórico alejado del consumo masificado, ¿podemos considerar que hacemos ${ }^{2}$ discursos alternativos? ¿A quién llegan

2. Me incluyo, dado que mi participación como sujeto de la investigación se mezcla con mi papel 
esos discursos y por qué son una alternativa? ¿Tienen algún impacto social? En resumen y más sencillamente: ¿sirve de algo producir un programa de radio feminista para un público que sabemos es reducido?

Parto de la hipótesis de que, sí, generamos una alternativa discursiva; de que, justamente porque salen de espacios minoritarios, cumplen con su función de ofrecer una vía de contrainformación y contrapoder; y de que el impacto que producen esos discursos es importante, una vez que las experiencias colectivas minoritarias inciden en las micropolíticas cotidianas. No se trata de discursos que vayan a llegar a las masas, pudiendo ser considerados, en momentos, un tanto elitista. Aunque no por eso pierden su carácter político y promotor de cambios de consciencia, generando posturas críticas hacia las relaciones de dominación, tanto en las personas que estamos involucradas en la experiencia colectiva como en nuestro entorno más cercano.

Por lo tanto, en el presente texto, pretendo abordar un caso concreto de producción de discursos alternativos a través del "hacer radio" con perspectiva feminista: el programa de radio Enredadas Mujeres, producción que se lleva a cabo en Radio Malva, una radio libre de la ciudad de Valencia, y de la cual participo activamente. Es mi intención tratar, brevemente, cómo surge dicha propuesta, desde dónde se habla y con qué intencionalidad y qué resultados se pueden sacar de un análisis crítico de esos discursos. También pretendo dar cuenta de la experiencia colectiva que supone esta praxis y de cómo ella incide tanto en la ampliación de redes de grupos feministas como en un proceso reflexivo por parte del colectivo social en el que está insertada. Espero, finalmente, poder ofrecer una contribución al análisis de cómo los discursos, a través de las tecnologías de la comunicación y de la sociedad red, ganan amplitud, pudiendo convertirse en medios de transformación, de enfrentamiento y crítica radical al discurso heteropatriarcal presente en los medios de comunicación generalistas.

\section{DE LA METODOLOGía Y MARCo TEÓRICo}

En el presente apartado, pretendo exponer algunas de las bases epistemológicas y teóricas necesarias para el desarrollo y comprensión del texto. Parto de la epistemología de los conocimientos situados (HARAWAY, 1995) y la enlazo

\footnotetext{
de objeto en la misma. Las fronteras entre sujeto y objeto aquí se difuminan en una apuesta por una experiencia colectiva y encarnada como campo de investigación, enmarcando el trabajo en los conocimientos situados (HARAWAY, 1995) como propuesta epistemológica.
}

REDES.COM N ${ }^{\circ} 11 \mid 75$ 
con el enfoque aportado por Martha Patricia Castañeda (2008). Castañeda encuentra en las distintas posturas teóricas respecto a una posible metodología feminista un punto de confluencia en el que "retomar la experiencia de las mujeres como recurso empírico y teórico se convierte en el rasgo distintivo de hacer investigación feminista" (CASTAÑEDA, 2008: 83). De esta forma, abogo por una metodología que acepte un análisis a partir de la experiencia colectiva feminista, con un enfoque parcial que pueda entender esa experiencia como un proceso continuo de deconstrucción del sistema de valores y relaciones de poder arraigadas socialmente.

Así, he realizado un análisis crítico del discurso, a partir del estudio de un caso concreto, el del programa de radio Enredadas, del que tuve en cuenta 40 programas, emitidos durante sus dos primeros años ${ }^{3}$. El análisis fue precedido por lo que Miguel S. Valles (1997) llamaría participación completa, es decir, la investigación ha surgido cuando yo, investigadora, ya era participante ordinaria de la situación. No obstante, en este artículo, me he centrado en presentar algunas claves discursivas que considero que sean rasgos pertinentes de los discursos que aquí tomo como alternativos.

Además de tener la experiencia colectiva feminista como punto de partida para el estudio, entiendo que la acción de investigar puede ser asumida como una práctica que antecede a la conciencia investigativa en sí, así como los problemas planteados no preceden a la selección de las unidades de análisis, derivando en una reorientación del pensamiento (CASTAÑEDA, 2008: 85).

Para el análisis del material, me he basado en la corriente del Análisis Crítico del Discurso, suplida, fundamentalmente, por textos de Teun Van Dijk (2001, 2009, 2010). Ese autor recuerda que gran parte de las investigaciones sociales se limitan a estudiar un problema y sus consecuencias, ofreciendo, además, la imagen de que asumen una postura neutral respecto a las posiciones sociales, políticas e ideológicas de la persona investigadora (VAN DIJK, 2009). Regreso, por lo tanto, a Haraway (1995), quien a mediados de los años 80 ya nos presentaba la epistemología de los conocimientos situados, aproximándonos de una perspectiva parcial como la capaz de darnos objetividad, a través de la cual asumir una postura y negar la neutralidad es asumir la responsabilidad y, por lo tanto, realizar un estudio verdaderamente crítico.

3. Este análisis lo he desarrollado de forma más extensa en Araújo Mendes (2012), donde también están documentadas entrevistas realizadas con las integrantes del programa Enredadas Mujeres, así como la revisión de materiales radiofónicos de dos radios generalistas del Estado español: Cadena Ser y Radiotelevisión Española (RTVE). 
En los conocimientos situados, además, se excluyen las barreras entre objeto de investigación e investigadora ${ }^{4}$. La distancia positivista establecida entre esas dos piezas claves de la investigación deja de ser fundamental, ya que lo primordial es reconocer que la investigadora y el objeto entablan una relación desde el principio y que el objeto deja de tener una posición pasiva para ser un agente de cambio en la investigación.

Esa es, precisamente, la postura que Van Dijk defiende como la característica de "crítico" en el estudio del discurso. La investigadora, en el estudio crítico del discurso, reconoce su compromiso y su posición en la investigación y en la sociedad y lleva a cabo su trabajo con el objetivo explícito de contribuir a producir un cambio social específico en favor de grupos dominados, una vez que se entiende las relaciones de dominación como el campo del uso de los discursos.

Así, parto de la consideración del lenguaje como una práctica esencialmente discursiva, en la que las relaciones entre texto, procesos de producción y reproducción y contextos sociales son los elementos fundamentales para la comprensión de las estructuras y de las relaciones de poder. Por lo que el Análisis Crítico del Discurso es una práctica que veo posible únicamente desde una perspectiva parcial y encarnada. Esto es, desde los conocimientos situados.

En cuanto al marco teórico, para fundamentar el papel de los discursos alternativos frente a los que considero dominantes y disciplinarios, es necesario tener en cuenta el concepto mismo de discurso, su construcción y su relación con las dinámicas de poder.

Con discurso me refiero a un conjunto de ideas que se rige bajo un sistema social de pensamientos (ColAIzzI, 1990; FOUCAULT, 2008, 1979; VAN DIJK, 2010, 2009, 2001). La práctica discursiva está tanto en la dimensión del uso del lenguaje como en la interacción social, y aquí me refiero al lenguaje en su carácter productivo y reproductivo y no meramente instrumental y representativo. A través del lenguaje, en sus distintos formatos, se manifiesta, a la vez que se construye, toda nuestra carga cultural. Ideas que, a su vez, subyacen a las relaciones de poder. De ahí que discurso y poder están intrínsecamente relacionados.

En dicha relación, entiendo que no existe un poder vertical y absoluto, sino que hay relaciones de poder que, así como los discursos, atraviesan nuestras cotidianidades, tal como lo defiende Foucault (2008, 1982, 1979, 1978).

4. He optado por utilizar el femenino genérico en todo el artículo como una alusión al sustantivo “persona(s)". Considero que son necesarios esfuerzos por hacer un uso no sexista de la lengua. Aunque dichos esfuerzos no se agotan con la estrategia aquí adoptada, considero que la incluyen y, por lo tanto, la asumo también como una postura política en el campo de la investigación académica. 
Dichas relaciones se manifiestan a través de unos discursos que legitiman la forma de organización social de una sociedad determinada: los valores, el conocimiento, el placer, la lengua etc. Discursos que podríamos decir que, en mayor o menor medida, nos han pautado las formas de vivir y relacionarnos, es decir, unos discursos disciplinarios (FOUCAULT, 1979, 1978).

Asimismo, de no existir un poder totalitario, aunque sí relaciones de poder predominantes, debemos tener en cuenta los ejercicios de contrapoder. Interesan aquí, especialmente, las prácticas de resistencia desde las micropolíticas (DELEUZE y GUATTARI, 1978, 1994), éstas vistas como el ejercicio político desde nuestras vivencias e interacciones personales y colectivas cotidianas y que se convierten en líneas de fuga ante el discurso y poderes disciplinarios. De ahí que amparo mi análisis también en la noción de comunidad (SEGARRA, 2012; GRASSET, 2012) aliada al concepto de minoritario (DELEUZE Y GUATTARI, 1978 , 1994). Por un lado, la comunidad entendida como un concepto subversivo que engloba lo heterogéneo y que, desde la pluralidad, "pone en entredicho el orden social, hace visible y amenaza su solidez" (SEGARRA, 2012: 20). Por otro, lo minoritario entendido como las condiciones revolucionarias que, desde articulaciones colectivas, se desarrollan en el seno del orden establecido (DELEUZE Y GUATTARI, 1978: 31).

Finalmente, entiendo que la relación entre discurso y poder se enmarca, principalmente, en el ámbito de la comunicación, por ser ésta el escenario por donde fluyen los discursos y, por tanto, donde están representadas las relaciones de poder. Parto del presupuesto de que la sociedad informacional (CASTELLS, 2000) es el paradigma de organización social vivido por los países occidentales y con amplio uso de las tecnologías de la información y de la comunicación, donde el proceso de generación, procesamiento y transmisión de la información penetra y transforma todas las acciones y relaciones humanas.

En dicho contexto, se han desarrollado fenómenos como la sociedad red y la autocomunicación de masas (CASTELLS, 2009). El primero traduce la idea de una estructura social global, pero también local, configurada por nodos que se interconectan principalmente a través de las tecnologías digitales de la información y de la comunicación en espacios simultáneos no contiguos y en flujos de tiempo atemporales (IBíD.). El segundo denomina el proceso que ha hecho que los medios de comunicación dejasen de ser bienes únicamente de consumo y que cada vez más personas se involucren en la producción y difusión de información, caracterizando lo que Castells denomina la audiencia creativa. Un proceso que tiene como base las transformaciones tecnológicas como Internet, el advenimiento de la comunicación digital, software cada vez más avanzados e interactivos, conexiones por banda ancha y terminales ina- 
ONDAS DIFERENCIALES PARA OTRAS INADECUADAS. FEMINISMOS, RADIO LIBRES Y DISCURSOS ALTERNATIVOS EN LA SOCIEDAD RED: EL CASO DEL PROGRAMA DE RADIO ENREDADAS MUJERES

lámbricos con acceso a Internet.

Sin embargo, considero que existe hoy un enaltecimiento de los aspectos positivos de dicho modelo de sociedad. Se habla en exceso de la capacidad para conectarnos con el mundo, pero es común obviar los debates sobre la brecha digital y sus variables, como el sexo, situación geopolítica, clase social o diversidad funcional; se incide en la cantidad y velocidad de la información, pero se trata muy poco de cómo en dicho volumen de información se repiten determinados patrones sociales, como las violencias por cuestiones de género a través del lenguaje y de conductas de acoso, o la continua objetificación de los cuerpos de las mujeres; se pone un énfasis excesivo en el soporte técnico utilizado para articular la comunicación entre las personas y se minimiza la capacidad de agencia de la población, sobre todo en el caso de las manifestaciones de carácter político reivindicativo.

En resumen, encuentro la necesidad de que se multipliquen las apreciaciones acerca de fenómenos como la sociedad red y la audiencia creativa y que sean reflexiones críticas que se salgan de la dicotomía tecnofobia/determinismo tecnológico. Teóricas como Judy Wajcman (2006), Remedios Zafra (2010a) o Igor Sádaba (2011) apuntan, en este sentido, hacia el desarrollo de una política de la tecnología que promueva una emancipación real de las personas. Una política que, como afirma Wajcman, "requiere algo más que hardware y software; requiere wetware - cuerpos, fluidos y agencia humana" (2006: 120).

Por lo tanto, considero que una política de la tecnología pasa por una práctica crítica de la comunicación, abogando por el desmantelamiento de las relaciones heteropatriarcales presentes en los medios. Una comunicación que se genera desde y por vías alternativas, desde núcleos de resistencias, de medios de comunicación independientes y, en el caso que nos atañe, desde las radios libres y de la contrainformación feminista.

\section{RADIO Y FEMINISMOS}

Al afirmar que una comunicación crítica y alternativa pasa por crear espacios de contrainformación, defiendo que éstos deben ser el reflejo de una práctica feminista cotidiana. Que sean espacios en los que se haga eco de voces que no suelen ocupar los medios de comunicación generalistas y que tengan un compromiso con el hacer política reivindicativa desde lo personal y de lo colectivo.

De ahí que dichos espacios surjan en ámbitos como los de las radios libres y comunitarias. Son espacios donde se busca un compromiso con una comu- 
nicación plural y con la información desde los márgenes y en pro de la práctica micropolítica de resistencia.

La radio como vehículo de comunicación social se convierte en una plataforma para los más distintos temas de debate. Sin embargo, como un medio de comunicación, la radio no está desprovista de una postura política. O aún como el escenario mismo donde interactúan las representaciones institucionales y no institucionales y se traban las relaciones de poder, como lo propone Castells (2009). Aún así, no deja de ser un contexto construido socialmente y que, por lo tanto, lleva unas improntas que no lo dejan neutro ante quienes actúan.

Así, cuando me refiero a una producción radiofónica feminista, estoy dejando patente la postura política que adoptamos las mujeres que construimos dichos programas de radio - las de Enredadas en concreto - , una postura que es, a la vez, la motivación fundamental para la creación de los mismos.

En este sentido, considero necesario articular algunas ideas sobre la perspectiva de género y del sujeto del feminismo que aquí utilizo. Así como Castañeda Salgado (2008), que postula que, cuando habla de mujeres como "sujetas cognoscentes", lo hace "pensando en su carácter generizado y situado" (IBíD., 64-66), también asumo que las mujeres que hacemos esos programas decidimos llevar a la práctica radiofónica parte de nuestros conocimientos académicos y militancia feminista. Nos asumimos como "mujeres feministas", desde una apropiación del sujeto "mujer" como una categoría política útil. Pero entendemos la complejidad y diversidad de dicha categoría, así como la que atraviesa el propio movimiento feminista, de ahí el uso del plural en ambos términos.

No podría arriesgar cualquier otro tipo de categorización, ya que estamos unidas por banderas mucho más generales, como la lucha contra las violencias machistas o la heteronormatividad, pero podemos llegar a tener posturas diversas respecto a un mismo tema o, incluso, identificarse con corrientes feministas distintas. Sin embargo, me considero afín a los debates propuestos por el transfeminismo y creo que, dada nuestra pluralidad en cuanto mujeres y feministas, es una perspectiva que se puede adecuar a nuestro contexto, en gran parte del tiempo.

El transfeminismo, como propone Emi Koyama (2001), nos invita a que repensemos nuestras ideas de a quiénes representamos y a qué representamos y "encarna la política feminista de coalición en la que mujeres con distintos antecedentes se respaldan mutuamente" (IBíd., 2) ${ }^{5}$. También la filósofa

5. Traducción de la propia autora. 
ONDAS DIFERENCIALES PARA OTRAS INADECUADAS. FEMINISMOS, RADIO LIBRES Y DISCURSOS ALTERNATIVOS EN LA SOCIEDAD RED: EL CASO DEL PROGRAMA DE RADIO ENREDADAS MUJERES

Sayak Valencia (2013) habla del transfeminismo como un espacio de articulación en el que el sujeto político deja de ser únicamente el cuerpo reconocido como femenino para dar lugar a una lucha encarnada por cuerpos plurales.

Por otro lado, cuando apunto a una perspectiva de género, me remito a Joan Scott (2011), quien aboga por el género como una categoría analítica útil. Scott defiende que dicha utilidad existe siempre y cuando lo tomemos como una invitación a pensar críticamente sobre las relaciones entre los cuerpos sexuados contextualizadas en el tiempo y espacio, relacionadas con las diversas estructuras organizativas sociales y a la vez con la forma con la que dichos cuerpos tienen de relacionarse con el mundo y con uno mismo.

Por lo tanto, cuando hablo de producciones radiofónicas feministas, me refiero a que son programas hechos por mujeres y con una intencionalidad política bien definida. Hablamos como cuerpos sexuados y generizados, localizados en unas relaciones de clase, étnicas y territoriales determinadas. Además, entendemos que las relaciones de género subyacen a las relaciones de poder y de dominación. Así que nos asumimos como sujetos generizados, pero comprendemos la necesidad de repensar y deconstruir esas categorías constantemente, a través de experiencias situadas, como pueden ser los discursos radiofónicos y desde un lugar de transgresión, como puede ser el transfeminismo.

Asimismo, los programas feministas a los que aquí me refiero se producen en el ámbito de las radios libres y/o comunitarias ${ }^{6}$, medios independientes, autogestionados (en el caso de las radios libres) y que suelen tener un compromiso con las luchas de los movimientos sociales. En cuanto a Enredadas, éste surge en una radio libre, por lo que dedicaré unos párrafos a explicar dicho concepto de radio.

En el Estado español, la definición de una radio libre tiene como referente el "Manifiesto de Villaverde", firmado en 1983, en Villaverde, Madrid (COORDINADORA DE RAdiOS LIBRES, 1983). El documento declara que las radios libres tienen un carácter no profesional, pues entienden que la comunicación no debe ser un medio de lucro, son autónomas, funcionan por la autogestión y el sistema asambleario. El concepto de "libre" viene de la apertura a la participación, estando el medio al servicio de la comunidad en la cual está integrada y, sobre todo, por el compromiso con una comunicación integradora, que reúna perspectivas plurales y, habitualmente, al margen de los medios generalistas. Adquieren, así, una responsabilidad con

6. Para un acercamiento a más programas de radio feministas, que no solo el del caso estudiado, ver el proyecto Red Nosotras en el Mundo (Red nosotras en el mundo, s.f.). 
los movimientos sociales que luchan contra los sistemas de dominación y opresión social.

La radio libre, en la que aquí quiero hacer hincapié, y de la cual Enredadas forma parte, es el Colectivo Radio Malva, con sede en los Poblados Marítimos de Valencia. Radio Malva se define como un proyecto de comunicación libre, asambleario y autogestionado, unido por "el desafío de crear y consolidar otra forma de comunicar e informar, solidaria, pluralista y diversa" (RADIO MALVA, S.F.). La radio emite en la frecuencia 104.9 FM y por Internet, a través de su blog, y cuenta actualmente con doce programas propios en la programación semanal, además de la retransmisión de programas e informativos de otras radios libres y medios independientes.

\section{PRODUCCIONES RADIOFÓNICAS FEMINISTAS EN EL CIBERESPACIO}

Los colectivos activistas y sobre todo los medios de comunicación independientes tienen como fuertes aliadas las herramientas para la comunicación disponibles actualmente. Éstas vienen marcando no solo los canales por los que comunicar, sino también la forma con la que los medios se relacionan con su público.

Las expresiones de sociabilidad están estrechamente conectadas al contexto histórico y sociocultural. En sociedades cambiantes, las formas de socialización también cambian, a la vez que influyen en las estructuras que conforman el espacio social. Josepa Cucó (2004) define sociabilidad como "los modos de interacción suprafamiliar y los agrupamientos que ocupan el espacio intermedio entre el nivel de las instituciones altamente formalizadas y el reducido ámbito de los grupos domésticos" y concreta que la función del espacio social es "dotar de especificidad a la trama organizativa de cada sociedad concreta” (IBíD., 125126). Así, Cucó pone de manifiesto el carácter mutuamente constitutivo entre sociedad y sociabilidad.

Por consiguiente, no es de extrañar que la sociedad informacional, fuertemente anclada en la revolución de las tecnologías de la información y de la comunicación, proporcione el surgimiento de nuevas formas de sociabilidad, bien como de nuevos espacios, como ya plasmaba Castells $(2000,2009)$ con el concepto de sociedad red.

Las redes sociales están insertadas en una dimensión social intermedia entre las relaciones y el sistema social, estando dicha dimensión integrada por los vínculos que unen a las personas en la vida cotidiana, con base en el intercambio recíproco de mensajes, bienes y servicios (cucó, 2004). Por otro lado, los vínculos, así como las formas de ejercer los intercambios, cambian como consecuencia de las nuevas tecnologías. 
ONDAS DIFERENCIALES PARA OTRAS INADECUADAS. FEMINISMOS, RADIO LIBRES Y DISCURSOS ALTERNATIVOS EN LA SOCIEDAD RED: EL CASO DEL PROGRAMA DE RADIO ENREDADAS MUJERES

Tal como la sociabilidad, también las demás estructuras de mediación social - el asociacionismo, las redes y los colectivos - van adquiriendo nuevos formatos y cambiando o sumando otras formas de expresión a lo largo del tiempo y con base en las evoluciones tecnológicas que marcan las sociedades.

Es lo que viene ocurriendo con los movimientos y los colectivos sociales de base, que han estado desarrollándose y sacando grandes ventajas de las redes virtuales. En el caso que nos atañe, la alianza entre feminismos y radios libres y/o comunitarias, utilizando las ventajas comunicativas de la sociedad red y del ciberespacio, vienen reiterando esas dinámicas y aportando contribuciones importantes.

Fenómenos como la audiencia creativa y el alcance del ciberespacio han permitido llevar a distintos ámbitos debates antes restringidos a colectivos feministas y/o a las personas geográficamente cercanas. En el caso de las prácticas radiofónicas, el alcance internacional proporcionado por el ciberespacio hace que, a su vez, estemos en contacto con otros colectivos y programas de radio feministas, promoviendo un intercambio de material, de reflexiones y retroalimentándonos en términos de contenido para las radios.

Cuando Sadie Plant (1998) llegó a afirmar que la Red Mundial de Ordenadores era esencialmente femenina, posiblemente cayó en un optimismo exagerado. No obstante, la Red, efectivamente, nos ha facilitado unas herramientas y un entorno que ha permitido el surgimiento de otro tipo de activismo feminista, tal como lo platearon Montserrat Boix y Ana de Miguel (2002), al hablarnos de un ciberfeminismo social, el activismo feminista en el ciberespacio, desde otros núcleos, que no únicamente el artístico manifestado por las primeras ciberfeministas ${ }^{7}$. Siguiendo la misma línea, podríamos referirnos a una comunicación social feminista. La comunicación a través de discursos alternativos, desde perspectivas feministas y de la contrainformación.

Siendo el contenido auto-gestionado, sin los filtros de censura de los grandes medios y teniendo plataformas de difusión gratuitas a nuestra disposición, el ciberespacio y las nuevas tecnologías se convierten en medio y herramientas de soporte para la promoción de discursos alternativos. No solamente en términos de alcance, sino también de creación de otros espacios, otras ondas, ondas diferenciales para otras inadecuadas. De hecho, coincido con Remedios Zafra (2010a), cuando afirma que superar las barreras

7. El colectivo vns Matrix $(1991,1996)$, Old Boys Network (1997), Faith Wilding \& Critical Art Ensemble (1998), Cornelia Sollfrank (2007). 
tradicionalmente asignadas en las producciones creativas de conocimiento no sería una tarea fácil sin "instrumentos deconstructivos y potencialmente reconfiguradores de espacios como Internet” (IBíD., 54).

En este sentido, las producciones radiofónicas feministas en el ciberespacio son una forma de seguir reivindicando ámbitos de lucha libres de la lógica del discurso heteropatriarcal que también predomina en la Red, así como en los movimientos sociales ${ }^{8}$.

Por otro lado, el ciberespacio, aunque virtualmente, ha producido el fin del aislamiento de innúmeras luchas. Creamos nuestros espacios particulares, pero nos conectamos a otros alrededor del globo, conformándose alianzas colectivas como una estrategia creativa (ZAFRA, 2010b) y de acción política. Dichas alianzas se convierten en ámbitos donde los vínculos políticos y la sororidad se mezclan en un activismo que atraviesa la esfera público-privada del "cuarto propio conectado" (ZAFRA, 2010a; 2010b).

\section{CONSTRUYENdo Discursos alternativos DESDE LAS PRODUCIO- NeS PROdUCCIONES RAdiofónicas FEMinistas: el CaSO PRÁCtico de ENREDADAS}

Así como los colectivos de contrainformación son espacios idóneos donde desarrollar una comunicación social feminista, también el ciberespacio se convierte en un entorno donde poder romper con las barreras geográficas y de la normatividad de los medios de comunicación generalistas.

A continuación, pretendo mostrar cómo son esos discursos alternativos y feministas en las producciones radiofónicas, a través del caso del programa de radio Enredadas. Abordaré el surgimiento de Enredadas y la forma como nos organizamos y producimos contenido. A la vez que haré un breve análisis crítico del discurso desarrollado en sus producciones.

\section{1. ENREDADAS: ¿CóMO SURGE?}

Enredadas es un programa de radio que surgió en el verano del 2010, producido por mujeres que buscábamos - y buscamos - tratar temas de la actualidad desde una perspectiva feminista, así como promover la discusión en torno a cuestiones típicamente invisibilizadas y/o estereotipadas en los medios de comunicación generalistas y en la sociedad.

8. Véase, por ejemplo, el caso de las comisiones feministas en las ocupaciones de las plazas con el 15-M (@joanaggrenzner et al., 2012). 
ONDAS DIFERENCIALES PARA OTRAS INADECUADAS. FEMINISMOS, RADIO LIBRES Y DISCURSOS ALTERNATIVOS EN LA SOCIEDAD RED: EL CASO DEL PROGRAMA DE RADIO ENREDADAS MUJERES

El programa se lleva a cabo desde Radio Malva, se emite en directo cada quince días y suele tener una duración de $1 \mathrm{~h} 30 \mathrm{~min}$. Una vez emitido en directo, la grabación del programa se sube a una plataforma en línea, especializada en compartir audios de forma gratuita. Además, Enredadas es también reemitido por Red Nosotras Radio ${ }^{9}$.

La propuesta de Enredadas surgió de dos compañeras del Máster de Género y Políticas de Igualdad de la Universitat de València, que querían llevar a la práctica radiofónica un poco de lo que se iba aprendiendo en las clases. Me sumé al proyecto y, juntas, lo presentamos al Colectivo Radio Malva. Tras haber presentado la propuesta, otras dos compañeras, que ya participaban del colectivo, se unieron a nosotras. Al final, éramos cinco mujeres, de las que sólo una era valenciana. Las demás éramos extranjeras, siendo una comunitaria y dos que no teníamos el castellano como lengua materna. De las cinco, tan solo una era periodista y con experiencia previa en radio. Las demás veníamos de distintas ramas de estudios y no teníamos formación en radio.

La idea era crear un espacio donde intercambiar experiencias desde una perspectiva feminista, compartir cómo vivíamos el proceso de aprendizaje, debatir temas de la actualidad, depurar nuestras sensaciones desde la poesía y de la música y primar que fuera un espacio plural, pero, sobre todo, un espacio de voces de mujeres y de deconstrucción continua del discurso heteropatriarcal.

Actualmente, de las cinco mujeres que empezamos, seguimos dos, dado que las demás compañeras tuvieron que retornar a sus países. En el 2012, tuvimos nuevas incorporaciones, además de que contamos con colaboraciones ocasionales de compañeras de otros espacios de activismo. De las que se fueron de Valencia, dos han seguido haciendo radio, en una idea de seguir Enredadas desde otros territorios. Así han surgido Enredadas Argentina y, más tarde, Enredadas México, con las que hemos mantenido el contacto, aunque las colaboraciones han sido menos frecuentes de lo que nos gustaría.

\subsection{LA PRODUCCIÓN RADIOFÓNICA DE ENREDADAS}

En Enredadas, hacemos programas temáticos y sin una estructura cerrada. Por programas temáticos, entendemos elegir un tema central y, a lo largo de la emisión, abordarlo de distintas formas. Bien sea a través de una ter-

9. Red Nosotras Radio forma parte de la iniciativa Red Nosotras en el Mundo, un proyecto de cooperación, especialmente radiofónica, que tiene como principal actividad la producción y difusión de audios feministas, con perspectiva de género y/o que recogen las voces de mujeres (Red nosotras en el mundo, s. f.).

REDES.COM N $\mathbf{0}^{\circ} 1185$ 
tulia, promoviendo un debate con invitadas, compartiendo noticias sobre el tema, emitiendo audios de otras radios o relacionando el tema con canciones y poemas.

Los temas abordados, hasta el momento, han estado en torno a las violencias que vivimos nosotras, mujeres. Pero no únicamente nosotras, mujeres blancas, jóvenes, europeas o no, heterosexuales, de clase media y con educación académica. Sabemos que, en muchos casos, hablamos desde una posición privilegiada. Así, intentamos que contribuyan mujeres que viven realidades distintas a las nuestras, con las que podamos aprender e intercambiar perspectivas diferentes y necesarias para reflexiones críticas. Aunque, en la práctica y para nuestro pesar, seamos casi siempre mujeres que cumplimos, más o menos, con el perfil descrito anteriormente. Un hecho que carece de mayores análisis.

La dinámica de los programas es más o menos estable: empezamos con una lectura de algún poema o manifiesto relacionado con la temática del día; pasamos a una revisión y crítica de lo que se ha dicho en los medios generalistas sobre el tema elegido y dedicamos la mayor parte del programa a debatirlo, aportando nuestras perspectivas personales, las de teóricas y/o expertas en el tema y las de otras colaboradoras o entrevistadas, cuando las hay.

La elección de la música también es una parte importante del programa. Las canciones son tratadas con el mismo criterio que tratamos los temas a debatir, ya que entendemos la música como una transmisora de información y, por lo tanto, constructora del debate social. Intentamos, así, que tengan un argumento relacionado con el programa del día y que sean cantadas por mujeres.

\subsection{ANÁLISIS CRÍtICO DEL DISCURSO DE ENREDADAS}

Retomando las motivaciones que nos llevaron a unirnos en el proyecto de Enredadas, es común que, entre nuestras conversaciones, volvamos a tocar la cuestión de que ya casi no escuchamos las radios generalistas, dado los motivos ya mencionados: constante invisibilización de las mujeres en los espacios radiofónicos y, principalmente, la (re)producción de discursos estereotipados, sexistas y victimistas (ARAújo MENDES, 2012). De ahí que considero que contribuir con debates desde perspectivas feministas, disonantes de las comúnmente presentes en los medios, sea una alternativa discursiva.

La concepción de discursos alternativos viene como una forma de poner en evidencia los mensajes presentes en los medios y que siguen recreando unas pautas de relaciones de dominación y de creencias heteropatriarcales. 
ONDAS DIFERENCIALES PARA OTRAS INADECUADAS. FEMINISMOS, RADIO LIBRES Y DISCURSOS ALTERNATIVOS EN LA SOCIEDAD RED: EL CASO DEL PROGRAMA DE RADIO ENREDADAS MUJERES

Es, además, una vía para la reflexión y autocrítica, en la medida en que nosotras mismas, en el proceso de producción, nos vamos percatando de cuán arraigada llevamos la cultura heteropatriarcal, así como generamos reflexiones acerca de cómo dicha cultura se reproduce en los mismos espacios politizados desde donde partimos.

A lo largo de los dos años analizados, hemos ido abordando cuestiones como: el amor romántico como factor de violencia y dominación heteropatriarcal; la precariedad laboral y la invisibilidad de las mujeres en las huelgas; economía feminista; la autodefensa feminista como respuesta a las distintas formas de violencia ejercidas sobre nosotras; los derechos de las trabajadoras del sexo; ciberfeminismo y empoderamiento a través de la Red; la invisibilidad de las mujeres en el arte; mujeres en la literatura, como escritoras y escritas; los trastornos alimentarios y como ellos se inscriben, sobre todo, en nuestros cuerpos de mujeres; las experiencias de mujeres migrantes; hablar de violencia desde/con mujeres del centro penitenciario de Picassent (Valencia); reflexiones sobre la intersexualidad; la violencia machista callejera; la experiencia de mujeres africanas por la integración; la violencia entre parejas lesbianas; el acoso virtual; homenajes a brujas y distintas mujeres que actuaron en diversos ámbitos; la menstruación eco-sostenible y el erotismo como forma de romper los modelos de sexualidad heteronormativos; la sexualidad de las mujeres mayores; entre otros.

Por otro lado, la forma en la que las problemáticas tratadas ganan voz es algo que define el tipo de discurso que buscamos construir: un discurso de denuncia, pero, sobre todo, dotado de agencia, alejándonos de las perspectivas victimistas. Intentamos, además, que otras mujeres puedan tener esa misma agencia, utilizando el espacio de Enredadas para hablar por ellas mismas. No queremos seguir hablando de otras, sino que "las otras" puedan dejar de ser objetos de los debates para ser sujetos en ellos, rompiendo con la forma en la que la violencia atraviesa nuestros cuerpos de mujeres. Aunque hay barreras que se pueden presentar, como puede ser la imposibilidad de llevar a trabajadoras sexuales al estudio, porque ellas prefieren no hacerlo, o la participación de mujeres presas, si no es desde el centro penitenciario. En estos casos, preferimos dejar lo más explícita posible nuestra postura de meras observadoras, de que no estamos en la piel de esas mujeres y, por lo tanto, no podemos hablar con propiedad, intentando no fraguar un discurso que victimice a las mujeres ausentes del debate.

Finalmente, del análisis de los audios de los dos primeros años de Enredadas, extraje cinco claves discursivas, que puntualizaré a continuación y que utilizaré como guías para el análisis crítico del discurso. 


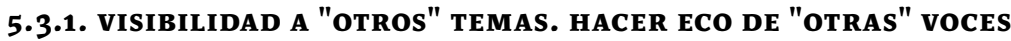

Como he mencionado, una de nuestras motivaciones y rasgo definitorio de un programa de corte feminista, producido y emitido desde una radio libre y a través del ciberespacio, es la posibilidad de tratar temas que no suelen estar presentes en las radios generalistas.

Los "otros" temas son precisamente las cuestiones invisibilizadas y que socialmente van perdiendo importancia. No porque no la tengan, sino porque, en la escala de las relaciones jerarquizadas y dictaminadas por los medios generalistas, se ha decidido que son cuestiones sin interés público. Por lo tanto, la alteridad a la que me refiero se presenta en tanto asuntos que surgen desde los bordes. Son "otros" porque son lo no-importante en la agenda pública.

Cuando se trata de visibilizar a las mujeres como protagonistas de la noticia y, sobre todo, como agentes de cambio, la alteridad ha estado presente. Y cuando se trata de visibilizar los feminismos, eso se da de forma aún más acentuada. Dicha dinámica se reproduce igualmente cuando las cuestiones son relativas a formas disidentes de vivir las relaciones sexo-afectivas, de manejar los sentimientos o de vivir la relación con el cuerpo. Por lo que, como Enredadas, decidimos situar nuestro campo temático desde la reapropiación de esta alteridad.

A título de ejemplo, está unos de los primeros programas que tenemos registrado, sobre amores románticos (ENREDADAS, AGOSTO DE 2010). El ideal de amor romántico no solo no suele ser reconocido como una de las bases de la violencia en las parejas, sino que, además, sigue siendo el modelo de relación ampliamente defendido y deseado.

En dicho programa se realizaron dos entrevistas, una presencial con la psicóloga y psicoterapeuta de terapia del reencuentro, Pau Pascual, y otra telefónica con la activista y profesora de cursos de autodefensa feminista, Maitena Monroy. En ambos casos, son entrevistas con mujeres que tienen una trayectoria importante de trabajo contra la violencia heteropatriarcal, pero que tampoco suelen estar presentes en los medios generalistas.

En las entrevistas, se hace un breve recorrido de cómo el amor entre parejas está planteado socialmente, de cómo nos educan a hombres y mujeres de manera distinta para el amor, los mecanismos y medios de transmisión de estos mensajes de ideal de amor romántico, los códigos que nos sitúan como personas incompletas y carentes de otras que nos complementen. Pero, sobre todo, de cómo se nos enseña a las mujeres que nosotras necesitamos este modelo de amor para vivir y ser "felices". Se abordan algunos de los códigos 
culturales que han servido para perpetuar el ideal de amor romántico, tales como cuentos, películas, cómics, música etc., y se relaciona esa búsqueda por el amor idealizado con las renuncias que terminamos por hacer cuando estamos en la relación y con la creencia de que todo sufrimiento, si es por "amor", es válido. Conductas que resultan en una relación donde el dolor y la violencia - que suele ser vivida por la mujer - son tolerados, como los sacrificios necesarios para una vida en pareja.

La forma como construimos nuestras relaciones amorosas, según el ideal romántico, están ancladas en la construcción y representación del género, en cómo las parejas, heterosexuales o no, cumplen con determinados perfiles: pasivo/activo, vulnerable/protector, abnegado/egoísta, emotivo/racional, etc., donde cada una de las personas asume uno de los extremos. Esas construcciones generizadas y dicotómicas respaldan la idea de que, en el amor, siempre una de las partes estará sometida y hará más concesiones. Por lo tanto, al igual que el género, el ideal de amor romántico es perpetuado a través de varias tecnologías y discursos institucionales (DE LAURETIS, 1989) y parainstitucionales: la música y la literatura, por ejemplo. A su vez, los medios de comunicación, como la radio, hacen uso recurrente de esas tecnologías y, por lo tanto, potencian esos discursos. Poner a debate los recursos utilizados para conservar el modelo de amor romántico y fomentar, entre todas, la discusión y el reconocimiento de formas distintas de vivir las relaciones es, por lo tanto, una manera de visibilizar otros temas en una producción radiofónica.

\subsubsection{PERSPECTIVA SITUADA}

Cuando optamos por hacer de Enredadas un espacio donde hablar desde nosotras mismas, hicimos una apuesta por imbuir el programa de una clara postura política feminista. A esta opción, añadimos el privilegio de una perspectiva parcial, situada, lo que implica la responsabilidad de ocupar un lugar específico en nuestras prácticas discursivas. Esto quiere decir que, haciendo un análisis crítico de los discursos de Enredadas, no se puede esperar una "neutralidad periodística". Ni la neutralidad es un elemento que asumimos como real, ni es periodismo lo que se hace desde los programas de Enredadas - por lo menos no en el sentido normativo - . Se hace comunicación social, política, arte y activismo feminista desde las ondas radiofónicas.

Tratamos de cuestiones que nos conciernen, como mujeres y como feministas. No obstante, somos conscientes de las variables y privilegios que condicionan nuestras subjetividades y experiencias vividas, tales como la raza, 
clase social, heterosexualidad, emplazamiento geográfico, etc. El interés particular por alguna temática, el hecho de que ésta nos remueve por algún motivo y que está a nuestro alcance se da porque, de una forma o de otra, forma parte de nuestras vidas. Sin embargo sabemos que no se pueden extrapolar a las realidades de todas las mujeres.

Así, decidimos ir localizando los discursos y las temáticas en realidades de las cuales formamos parte. Un recurso que nos ha permitido más honestidad y propiedad en los argumentos. Aunque queramos apoyar otros ámbitos de lucha de los feminismos, al no disponer de los recursos necesarios - bagaje teórico, práctico y/o colaboraciones externas -, optamos por situar nuestras perspectivas y acotar el campo argumentativo a lo que nos atañe y a cómo nos atañe. Esta es también la forma de reconocer las limitaciones de nuestras prácticas.

\section{3·3. MÚSICA QUE IMPORTA}

En las emisiones, intentamos que las canciones utilizadas sean parte importante del contenido de los programas. Que, más que servir como puntuación, marcando pausas, sean también parte del mensaje que queremos transmitir. Por lo que solemos elegir las canciones con el mismo criterio dedicado a los temas y procuramos que ambos estén relacionados.

La música es uno de los elementos radiofónicos por excelencia. Ha estado presente desde los orígenes de la radio, con retransmisiones de conciertos, actuaciones en directo desde los propios estudios y formando parte de la programación diaria de las emisoras (RODRÍGUEZ BORGES, 2006).

La música, además, es un componente que refleja nuestro estado de ánimo. Dialoga con nuestros sentimientos y valores y, así como los medios de comunicación, es un canal para transmitir información, reproducir y perpetuar discursos dominantes. Tiene influencia en la socialización de las personas, en la educación que recibimos.

Lucy Green (2001) habla de dos aspectos del significado musical: el significado intrínseco y el evocado. El primero se refiere a los sonidos de la música, o lo que ella llama materiales musicales, y a cómo éstos se interrelacionan en una pieza musical, derivando en la experiencia vivida por las oyentes:"los materiales musicales pueden dar lugar a la sensación del todo y de la parte, de la obertura y el final, la repetición, la semejanza, la diferencia o cualesquiera otras relaciones funcionales pertinentes en el oyente" (IBíD., 17). El segundo se refiere al contexto y a los factores simbólicos esbozados por la música, "consisten en connotaciones o asociaciones que se derivan 
de la postura y el uso de la música en un contexto social" (IBíd., 21). Los dos procesos son dialécticos y ambos son artificiales, históricos y aprendidos.

Otro concepto trabajado por Green es el de patriarcado musical, que influye directamente en la historia de las prácticas musicales de las mujeres, como puede ser la invisibilización de éstas en los estudios de la música - aquí la autora hace referencia al cupo de compositores occidentales clásicos, varones - $\mathrm{O}$ en cómo se extiende al ámbito musical la división sexual del trabajo, en cuanto a las esferas del público y de lo privado y de la reproducción de roles musicales masculinizados y feminizados: por ejemplo, el uso de la imagen y cuerpo de la mujer, que suelen ser las vocalistas en los grupos musicales, mientras, por lo general, los instrumentos son tocados por hombres.

Los aspectos descritos por Green dialogan con los discursos dominantes y disciplinarios, contribuyendo a la (re)creación de un imaginario social, de estereotipos, de roles de género y de las relaciones poder, donde mujeres y hombres (por no mencionar otras identidades de género) ocupan lugares diferenciados y desiguales en la música. Virginia Guarinos (2008), por ejemplo, pone luz sobre investigaciones realizadas por la International Association for the Study of Popular Music (IASPM), que han encontrado relaciones entre la objetualización sexual de las mujeres en canciones y daños en la autoimagen, como: timidez, ansiedad, trastornos alimentarios y depresión. En el mismo programa de Enredadas sobre amores románticos, las invitadas a tratar del tema nos hablaron sobre la construcción cultural del ideal de amor romántico y de cómo éste se va arraigando a través de la literatura, de la música etc.

Así, creyendo en la música también como un vehículo de comunicación y siendo éste un recurso de importancia en las emisiones radiofónicas, una de las prerrogativas de Enredadas, desde sus inicios, es darle la vuelta a la actual emisión masiva de canciones que generan soportes al sistema heteropatriarcal. La música, por lo tanto, es también una forma de ejercer el contrapoder y de promover discursos alternativos. Canciones contestatarias, con letras de denuncia y que empoderan, que desmantelan el modelo de mujeres víctimas, de mujeres cuyo único objetivo es vivir un romance, esperar el otro o que sufren por amor. Sobre todo, intentamos, al máximo, dar visibilidad a música hecha e interpretada por mujeres. Decantándonos, además, por grupos y cantantes que no se mueven por la industria musical dominante y que priman por producciones independientes, aunque esta última cuestión no sea un pre-requisito. 


\subsubsection{DESVICTIMIZACIÓN DE LAS MUJERES: MENSAJES QUE EMPODERAN}

La deconstrucción de la imagen "mujer víctima" es otra de las claves que consideramos esencial para que el discurso sea considerado alternativo. Los medios de comunicación generalistas, en su mayoría, siguen presentando las mujeres, constantemente, como víctimas de la violencia machista. Se contabilizan las cifras de casos de violencia, como si combatir el heteropatriarcado consistiera en eso. Además, mientras se visibiliza la continua violencia, se omiten acciones que se realizan con el objetivo de desmontar las estructuras en las que se basan las agresiones, de empoderar a las mujeres, concienciar la ciudadanía y contribuir al cambio cultural.

En este sentido, se han llevado a cabo programas que narran, por ejemplo, la experiencia de la Asociación por la Integración de las Mujeres Africanas en Valencia (ASIMAV) (ENREDADAS, ABRIL DE 2012), en el cual contamos con la participación de dos mujeres de la misma asociación, Mariam y Oumou.

Considero importante señalar cómo la participación de las dos mujeres es, en sí misma, una ruptura con el modelo de mujeres africanas victimizadas. Son mujeres que no tienen el castellano como primer o segundo idioma, sin embargo van a una radio y no se inhiben ante un micrófono. Además, las experiencias son contadas en primera persona, siendo ellas las voces activas.

También cambian los estereotipos de mujeres sumisas, dado que ellas decidieron crear una asociación de mujeres, aun cuando ya hay una asociación de países africanos por la integración en la ciudad. Cuentan cómo ellas mismas montaron una obra de teatro con el objetivo de sensibilizar a las personas, africanas o no, sobre las violencias que ejercen sobre las mujeres en sus países. Y, sobre todo, son capaces de hablar de todo eso abiertamente, conscientes de que ellas pueden ser agentes de cambio.

\subsubsection{FUGACIDAD Y COMPATIBILIDAD REDEFINIDAS}

La última clave que quiero destacar hace referencia a dos rasgos de la radio como medio, y que se incorporan como elementos determinantes del mensaje radiofónico: la fugacidad y compatibilidad (RODRÍGUEZ BORGES, 2006). Entre otras características del medio radiofónico, estos dos, especialmente, se han transformado con la reconfiguración del modelo de radio que trajeron las nuevas tecnologías. Aquí quiero dejar patente cómo considero que esos cambios afectan la articulación del discurso radiofónico.

Rodríguez Borges nos recuerda que "esa cadena de sonidos que nos trasladan las ondas tiene una vida efímera, el tiempo que tardan en desvane- 
ONDAS DIFERENCIALES PARA OTRAS INADECUADAS. FEMINISMOS, RADIO LIBRES Y DISCURSOS ALTERNATIVOS EN LA SOCIEDAD RED: EL CASO DEL PROGRAMA DE RADIO ENREDADAS MUJERES

cerse en el aire" (2006: 97). La fugacidad de los mensajes transmitidos por la radio hacía que la información radiofónica tendiera a la economía textual, a una exigencia de brevedad, claridad y sencillez en la exposición. Por otro lado, la radio no reclama una atención exclusiva, habiendo la posibilidad de compatibilizar el acto de escucharla con otras actividades diarias.

Dichos aspectos nos llevan directamente al contexto de la sociedad informacional y de las tecnologías de la comunicación. Las emisiones de radio ya no se hacen exclusivamente por cadena, sino también por Internet, además, los programas grabados son almacenados en directorios en línea y puestos a disposición del público. Las radios libres, sobre todo, y los colectivos sociales son grandes beneficiarios de las facilidades con las que se pueden gestionar dichos procesos actualmente, dado que los medios que los posibilitan son cada vez más accesibles, tanto desde el punto de vista técnico como económico.

La posibilidad de crear directorios que reúnen los audios (los podcast) y que están disponibles para que podamos escucharlos en cualquier momento hace, sobre todo, que la relación de las personas usuarias habituales de Internet con las radios cambie en definitiva. De ahí que fugacidad y compatibilidad, en el mundo de los podcasts, se redefinen. Se redefinen los tiempos: para la generación de usuarias de Internet que ya no cuenta con la televisión o la radio tradicionales como principales vehículos de información, se instaura la autogestión del tiempo. Se rompe con el consumo diacrónico de los medios y se instaura una mayor selectividad en el momento de elegir qué y cuándo se escucha o se ve algo.

De la misma forma, antes los elementos fugacidad y compatibilidad también eran determinantes en la redacción de los textos radiofónicos, con mensajes amenos y de poca profundidad teórica. Pero dado que, al escuchar un podcast, se hace una autogestión de la escucha, nos podemos permitir mensajes más desarrollados, de un contenido teórico más elevado. Escuchar un podcast se puede convertir en una actividad prioritaria, en la que poner más atención y realizada mediante una planificación horaria.

Aunque la compatibilidad pueda ser considerada una ventaja de la radio, cuando compatibilizamos otras actividades con la escucha, pasa lo mismo que cuando se conversa con alguien mientras se escucha una acción: en algún momento, la atención está más en una cosa que en otra y, por ejemplo, se puede perder parte de lo que se ha dicho; no porque no se estuviera escuchando, sino porque el foco no estaba en la conversación. Con lo cual, con el podcast, se puede convertir la acción de escuchar la radio en actividad primaria, no complementaria, haciendo de la escucha un ejercicio con atención. 


\section{CONSIDERACIONES FINALES: EL IMPACTO DE LOS DISCURSOS RADIOFÓ- NICOS FEMINISTAS}

En cuanto un programa de temática feminista y partícipe de un colectivo de comunicación asambleario, que hace una radio libre, no normativa, una de las motivaciones que me llevaron a plantear el presente trabajo fue el querer saber el impacto real de lo que hacemos. Si somos una minoría, aislada y que no dialoga con la sociedad o si, aun siendo minoría, cumplimos con la función que aspiramos: hacer comunicación social con perspectiva feminista y contrainformar; poner en evidencia los discursos heteropatriarcales y promover alternativas.

Es posible que no se pueda medir el impacto y no creo que se deba, al menos no de forma meramente cuantificable. Aquí, la experiencia cuenta. Es necesario pensar desde la diferencia, desde las posibilidades de subversión de lo minoritario (DELEUZE y GUATTARI, 1978), de las alianzas que se crean y del devenir-comunitario heterogéneo (SEGARRA, 2012). Esto no es cuantificable. Tampoco lo es el proceso de empoderamiento individual de cada persona que llega a participar de una producción radiofónica feminista. Ni las aportaciones a los debates y críticas internas que llevan la perspectiva feminista al funcionamiento de los colectivos activistas. Lo que sí se podría poner en números, respecto a la audiencia de los programas, puede ser considerado irrisorio, desde el punto de vista de las cifras. Sin embargo, la concienciación del entorno y las posibilidades de asociacionismo que se generan con la pequeña audiencia no pasan desapercibidas.

Lo común, un proyecto colectivo, la apuesta por la construcción de algo entre todas es, en sí mismo, un impacto contra el sistema dominante. De ahí la necesidad de rescatar la noción de comunidad (SEGARRA, 2012; GRASSET, 2012) como concepto de colectividad y asociacionismo, siendo éstas características también de un devenir-minoritario (DELEUZE Y GUATTARI, 1978) y que las traigo a una reflexión sobre la experiencia feminista desde el universo radiofónico como práctica minoritaria.

Deleuze y Guattari abordan la idea de minoritario a partir de lo que ellos denominan literatura menor, a la que atribuyen tres características: la desterritorialización de la lengua, la articulación de lo individual en lo inmediato-político y el dispositivo colectivo de enunciación (1978: 31). A continuación, expondré una breve reflexión en torno a dichas características trasladándolas a las experiencias feministas y a la práctica radiofónica.

Respecto a la desterritorialización de la lengua, los autores presentan una literatura escrita en un entorno marginal, que no pertenece a lo normativo, 
ONDAS DIFERENCIALES PARA OTRAS INADECUADAS. FEMINISMOS, RADIO LIBRES Y DISCURSOS ALTERNATIVOS EN LA SOCIEDAD RED: EL CASO DEL PROGRAMA DE RADIO ENREDADAS MUJERES

aunque forma parte de él. En este sentido, planteo aquí que un proceso similar se vive con la reapropiación del idioma que se hace desde las propuestas feministas. Subvertir lo normativo, utilizando femeninos genéricos o genéricos desgenerizados. Pervirtiendo la semántica de las palabras, dándoles connotaciones distintas a las normativas o recuperando lo que se ha perdido de ellas en el proceso de patriarcalización del idioma. Si la lengua como institución, homogeneizada y estandarizada, es un ejercicio de dominación (GRASSET, 2012: 59), romper con los cánones idiomáticos sexistas es también un ejercicio de insumisión a las leyes sociales.

Por lo que corresponde a la articulación de lo individual en lo inmediatopolítico, Deleuze y Guattari afirman que, en las literaturas menores, todo es político, cada problema individual es de todas. En este caso, no queda más que recordar uno de los lemas más presentes en los feminismos: "lo personal es político", además de la apuesta por las micropolíticas, cuestionando las relaciones de poder cotidianas. Es también una de las premisas de Enredadas, pues entendemos que los temas abordados extrapolan lo privado y se convierten en reivindicaciones políticas en el momento en que asumimos la propuesta como colectiva. Así como lo es también el proceso de empoderamiento por el que pasamos cada una de nosotras en el "hacer radio".

Respecto al dispositivo colectivo de enunciación, es un planteamiento estrechamente conectado con el anterior. Dado que la marginación y la colectividad reducida hacen de lo individual una cuestión política, en la literatura menor, "todo adquiere un valor colectivo" (DELEUZE Y GUATTARI, 1978: 30).

Si bien Deleuze y Guattari abordan la idea de minoría, de lengua mayor y menor desde la literatura y que Grasset (2012) nos hace un paralelismo con cómo estos conceptos contribuyen a configurar la noción de comunidad, me valgo también de la lengua menor para transportarla al universo de las radios libres y de las producciones feministas.

Grasset afirma que la variación continua de la lengua, a la que se refieren Deleuze y Guattari, es una alusión a lo que él considera una misión de todo escritor: encontrar su voz propia, "el proceso, del cual el escritor no conseguirá desprenderse, pasará por la suspensión de la supuesta relación estable que mantiene con su propia lengua" (IBíd., 59).

Aquí abogo por una línea de fuga, una búsqueda por romper con el orden social a través de producciones radiofónicas minoritarias, ofreciendo la producción colectiva como un discurso alternativo. Así como Grasset afirma que "toda literatura menor es una escritura colectiva" y, por tanto, "constituye una acción política y comunitaria" (IBíD., 60), defiendo que toda producción de radio feminista es un ejercicio minoritario del lenguaje y, por tanto, una 
línea de escape al orden heteropatriarcal y a los medios de comunicación generalistas y sus discursos disciplinarios.

Las producciones feministas forman parte de un universo de lengua menor, donde la desterritorialización y la articulación personal/político e individual/colectivo son parte de su corpus. Deleuze y Guattari afirmaban que "lo que equivale a decir 'menor' no califica ya a ciertas literaturas, sino las condiciones revolucionarias de cualquier literatura en el seno de la llamada mayor (o establecida)" (1978: 31). De la misma forma se califican las producciones radiofónicas feministas, desde los bordes y promoviendo las condiciones para subvertir el aparato mediático "mayor" (heteropatriarcal).

El proceso de empoderamiento personal a través del uso de la voz es una segunda consideración que hago respecto a los impactos que puedan tener los discursos radiofónicos feministas. Ciertamente, a pequeña escala. En este caso, abogo, una vez más, por la experiencia propia de un pequeño colectivo como el de Enredadas y sus colaboradoras.

Vuelvo a hacer uso de algunos recursos del análisis literario para discurrir sobre el discurso radiofónico. En este caso, de la relación que Hélène Cixous (1995) establece de la escritura como una prolongación de la voz y viceversa. Cixous afirma que la escritura pasa por un privilegio de la voz, "escritura y voz se trenzan, se traman y se intercambian, continuidad de la escritura" (IBíd., 54). En el caso de la práctica en la radio, es de la voz propiamente de la que estamos hablando.

Afirma Cixous que, para la mujer, hablar en público, o el mero hecho de abrir la boca, es una transgresión (IBÍD., 55). Es vivir la toma de la palabra oral como un proceso personal-político, "toda ella se convierte en su voz, sostiene vitalmente la 'lógica' de su discurso con su propio cuerpo" (IBíd., 55). Esta relación tan vital con la voz, tan corpórea como dialéctica, es lo que hace que la experiencia radiofónica sea tan íntima para nosotras.

Las barreras que se rompen cuando tomamos la palabra son, igualmente, barreras múltiples y que no están presentes solo en la relación mujer-micrófono-oyentes. Están en las distintas relaciones entre las mujeres, la voz, el cuerpo, los niveles de auto-exigencia y de auto-aceptación. De hecho, considero que son dos, por lo menos, las etapas del proceso de toma de la palabra a través de la radio: el enunciarla, exteriorizarla, sacarla de lo privado a lo público; y la vuelta a ella, escucharnos a nosotras mismas, aceptarnos y aceptar nuestra palabra.

Cixous pregunta “¿por qué hay tan pocos textos?", a la vez que contesta, "porque aún muy pocas mujeres recuperan su cuerpo" (IBÍD., 58). Además del llegar a apropiarse de los micrófonos, una de las barreras con la que nos 
ONDAS DIFERENCIALES PARA OTRAS INADECUADAS. FEMINISMOS, RADIO LIBRES Y DISCURSOS ALTERNATIVOS EN LA SOCIEDAD RED: EL CASO DEL PROGRAMA DE RADIO ENREDADAS MUJERES

hemos encontrado entre nosotras es el ejercicio de escuchar nuestros programas ya grabados y, por lo tanto, escucharnos a nosotras mismas. Creo que este miedo a volver a la voz tiene que ver con la separación que menciona Cixous, de que "nos hemos apartado de nuestros cuerpos, que vergonzosamente nos han enseñado a ignorar, a azotarlo con el monstruo llamado pudor" (IBÍD., 58).

De ahí que el hacer radio, sobre todo con las facilidades de estos tiempos, tiempos del podcast, se ha convertido en una herramienta potencial, a través de la cual las dos fases, la enunciación y el retorno a la voz, se unifican en un proceso técnicamente sencillo y ofrecen una vía de desmantelamiento de los pudores instaurados en nuestros cuerpos y, por lo tanto, de empoderamiento. En la privacidad de nuestras habitaciones, de nuestros cuartos propios conectados (ZAFRA, 2010a), vamos rompiendo las barreras del pudor y aceptándonos, primero en lo íntimo, luego en lo colectivo.

Cixous también habla de los silencios, "la caída en la pérdida del lenguaje" (IBíD., 55), como una experiencia por la que toda mujer ha pasado en el camino hacia la palabra oral. En las producciones de Enredadas, como también he observado en otras producciones (desde la oferta de Red Nosotras en el Mundo, por ejemplo), son comunes los silencios.

Como bien lo afirma Cixous, no estamos acostumbradas a hacer uso de la retórica, pero tampoco a hacer las cosas sin placer, "sólo mantenemos un discurso a un cierto precio" (IBíD., 55). Y aunque Cixous aboga por los aspectos positivos en dejar la lengua intentar y en los desperdicios de lo que decimos, pienso que es igualmente importante respetar nuestros silencios. No entendiéndolos como una forma de privarnos de la voz, sino como una forma de reflexividad y también como parte de nuestro proceso hacia la práctica retórica.

Este silencio necesario conecta también con la crítica a la velocidad informativa que satura, propuesta por Zafra (2010a), y que es una de las contrapartidas de la sociedad red. La velocidad, según Zafra, nos lleva a la pérdida de la distancia necesaria para una actitud crítica (IBíD., 167). El bombardeo de información a través de los medios audiovisuales, saturándonos con mensajes, se sustenta, sobre todo, en ideas preconcebidas, pues son las que no necesitan tiempo para configurarse - dado que son ideas que ya las tenemos bastante arraigadas - . De ahí que esa celeridad ayude a reforzar los discursos y valores disciplinarios. Cuando desaceleramos, en este caso, cuando consentimos el silencio, nos permitimos volver a la "distancia crítica y su posibilidad imaginativa” (IBÍD., 168). Parafraseando a Zafra: aprender a saber callar supondría una interpelación del tiempo propio y el pensamiento interior no sólo más allá de la memoria, sino también más allá de la presión del instante. 
Volviendo a Cixous, también ella nos habla de inventarse una lengua, de desapropiación y despersonalización, de que "si la mujer siempre ha funcionado 'en' el discurso del hombre (...) ha llegado ya el momento de que disloque ese 'en', (...) le dé la vuelta y se apodere de él, (...) que se invente una lengua para adentrarse en él" (ibíd., 59). Lo que me devuelve al devenir-minoritario de Deleuze y Guattari y su apuesta por el que una debe ser bilingüe en su propia lengua.

En este sentido, creo que la toma de la palabra oral, el hacer resonar nuestras voces y aceptarnos en el momento en el que volvemos a escucharnos es, en sí mismo, parte del ser bilingüe, de la transgresión del lenguaje institucionalizado y descubrimiento de nuestra lengua menor. Por lo que uno de los impactos producidos por un discurso radiofónico feminista es la misma práctica discursiva.

Además de las vías de empoderamiento promovidas por el hacer radio y por las alianzas generadas de ahí, un programa radiofónico feminista también aporta una importante dosis de autocrítica a la práctica de la contrainformación. Es de notar que, en muchos colectivos activistas por una comunicación libre, la perspectiva feminista real parece que sigue siendo una asignatura pendiente.

Por último, conviene hablar de la audiencia de los programas. En términos de números, Radio Malva, como la mayoría de radios libres y comunitarias, no tiene formas de medir el índice de audiencia en directo, por antena. Aunque sí podemos ver la cantidad de personas que nos escuchan vía emisión en línea.

Pese a la importancia de emitir por antena, lo más probable es que un programa como Enredadas tenga mucho más seguidoras a través del ciberespacio, sobre todo por las alianzas que se van haciendo y por la divulgación posterior a la emisión en directo, cuando ponemos a disposición de la Red los audios grabados. De esta forma, a través de la plataforma donde alojamos los archivos, es posible ver cuántas veces cada programa fue escuchado y/o descargado (pocas veces sobrepasa las 50 descargas, salvo algunos programas puntuales). Aún así, incluso la audiencia en línea nos deja sin datos completos, ya que, desde enero de 2012, los programas de Enredadas también son retransmitidos por Red Nosotras Radio.

Dadas las herramientas que tenemos disponibles, hacer comunicación social hoy implica hacernos audibles por la Red, pero también hacernos visibles en el ciberespacio, en las redes sociales en línea. Sobre todo las producciones desde radios libres, pues es la forma más barata y eficaz de sobrepasar las barreras de nuestras limitaciones técnicas y económicas. Y aunque tuviéramos, por antena, el mismo alcance territorial de los medios generalistas, la actuación en la Red nos permite extendernos hacia cualquier rincón del planeta donde haya un ordenador conectado a Internet. 
ONDAS DIFERENCIALES PARA OTRAS INADECUADAS. FEMINISMOS, RADIO LIBRES Y DISCURSOS ALTERNATIVOS EN LA SOCIEDAD RED: EL CASO DEL PROGRAMA DE RADIO ENREDADAS MUJERES

Por otro lado, es cierto que, si ampliamos las alianzas y cada vez más personas pasan a escuchar programas como Enredadas, la mayoría de esas personas sigue siendo parte de una población con alguna consciencia previa en temáticas de género, lo que podría indicar un riesgo a una deriva anti-social. No obstante, no quiere decir que el discurso de Enredadas no produzca cambios.

Sabemos que ni Radio Malva ni Enredadas es o será un medio masificado. Su papel, en cuanto foco de resistencia, de contrapoder y de producción de discursos alternativos está en actuar desde lo minoritario, generando consciencia colectiva en un espacio situado. Por lo tanto, apostando por que, por tener una actuación más cercana, se promueva un cambio estructural, en las microestructuras de nuestras políticas cotidianas y generando transformaciones personales en mayor profundidad. No son debates epidérmicos, sino la generación de una consciencia crítica que, a su vez, produce una postura contestataria e inconformista hacia los discursos heteropatriarcales que subyacen a las relaciones de poder.

\section{REFERENCIAS BIBLIOGRÁFICAS}

@JOANAGGRENZNER, Setas Feministas, Grupo Clío, Assemlea Feministes Indignades, Feministas bastardas, \#AcampadaObradoiro, Comisión Transfeminista 15-M, Comisión feminismos Sol (2012). R-Evolucionando. Feminismos en el 15-M, Barcelona: Icaria Editorial.

ARAÚJO MENDES, JÚLIA (2012). Discursos alternativos en la sociedad-red: Enredad@s, la experiencia de un programa de radio feminista. (Trabajo de fin de máster inédito). Universitat de València, Institud Universitari d'Estudis de la Dona, España. Dirección http://roderic.uv.es/handle/10550/34822 (Última consulta: 12 de febrero de 2015).

BOIX, MONTSERRAT Y DE MIGUEL, ANA (2002). Los géneros de la red: los ciberfeminismos. Dirección http://www.nodo50.org/mujeresred/spip. php?article297 (Última consulta: 20 de octubre de 2014).

CASTELLS, Manuel (2000). La era de la información: Economía, Sociedad y Cultura. Volumen 1: La sociedad red, Madrid: Alianza, $2^{\mathrm{a}}$ ed.

CASTELLS, MANUEL (2009). Comunicación y Poder, Madrid: Alianza.

CASTAÑEDA SALGADO, MARTHA PATRICIA (2008). Metodología de la investigación feminista, México, DF.: Centro de Investigaciones Interdisciplinarias en Ciencias y Humanidades (CEIIHC) de la Universidad Nacional Autónoma de México (UNAM). 
CIXOUS, HÉLÈNE (1995). La risa de la medusa. Ensayos sobre la escritura, Barcelona: Anthropos; Madrid: Dirección General de la Mujer; San Juan: Universidad de Puerto Rico.

COLAIZZI, GIULIA (1990). Feminismo y teoría del discurso: razones para un debate en COLAIZZI, Giulia (ed.) (1990). Feminismo y teoría del discurso, Madrid: Cátedra, pp. 13-28.

COORDINADORA DE RADIOS LIBRES (1983). Manifiesto de Villaverde. Dirección: http://www.sindominio.net/radiotopo/article.php3?id_article $=5$ (Última consulta: 20 de octubre de 2014).

CUCÓ, JOSEPA (2004). Las estructuras de mediación en CUCÓ, Josepa (2004). Antropología Urbana, Barcelona: Ariel.

DE LAURETIS, TERESA (1989). La tecnología del género en DE LAURETIS, Teresa (1989). Technologies of gender. Essays on Theory, Film and Fiction, London, Macmillan Press, pp. 1-30. Dirección: http://wiki.medialab-prado. es/images/b/bo/La_tech_del_genero_Delauretis.pdf (Última consulta: 21 de octubre de 2014).

DELEUZE, GILLES, GUATTARI, FÉLIX (1978). Kafka. Por una literatura menor, México D.F.: Ediciones Era.

DELEUZE, GILLES, GUATTARI, FÉLIX (1994). 1933 - Micropolítica y Segmentaridad en DELEUZE, Gilles y GUATTARI, Félix (1994). Mil mesetas. Capitalismo y esquizofrenia, Valencia: Pre-Textos, 2a. ed., pp. 214-237.

ENREDADAS (equipo productor). (agosto de 2010). Amores románticos como dominación patriarcal. [Audio en podcast]. Dirección: http://www.ivoox. com/amores-romanticos-como-dominacion-patriarcal-audios-mp3_ rf_383715_1.html (Última consulta: 24 de octubre de 2014).

ENREDADAS (equipo productor) (abril de 2012). Asociación por la integración de mujeres africanas. [Audio en podcast]. Dirección: http://www.ivoox.com/ asociacion-integracion-mujeres-africanas-audios-mp3_rf_1193011_1.html (Última consulta: 27 de octubre de 2014).

FOUCAULT, MICHEL (1978). Microfísica del poder, Madrid: La Piqueta.

FOUCAULT, MICHEL (1979). Vigilar y castigar. Nacimiento de la prisión, Madrid: Siglo XXI.

FOUCAULT, MICHEL (1982). Afterword: The Subject and the Power en DREYFUS, Hubert L. y RABINOW, Paul (1982). Michel Foucault: Beyond Structuralism and Hermeneutics, Brighton (Sussex): The Harvest Press Ltd. FOUCAULT, MICHEL (2008). El orden del discurso, Barcelona: Fábula, $4^{\mathrm{a}}$ ed. GREEN, LUCY (2001). Música, género y educación, Madrid: Ed. Morata.

GRASSET, ELOI (2012). Necesitar devenir-minoritario: sexualidad, territorio y escritura en SEGARRA, Marta (ed.) (2012). Repensar la comunidad desde la 
ONDAS DIFERENCIALES PARA OTRAS INADECUADAS. FEMINISMOS, RADIO LIBRES Y DISCURSOS ALTERNATIVOS EN LA SOCIEDAD RED: EL CASO DEL PROGRAMA DE RADIO ENREDADAS MUJERES

literatura y el género, Barcelona: Icaria Editorial.

GUARINOS, VIRGINIA (2008). Mujer, Radio y Canción de Consumo en LOSCERTALES ABRIL, Felicidad y NÚÑEZ-DOMÍNGUEZ, Trinidad (coord.) (2008). Los medios de comunicación con mirada de género, Sevilla: Instituto Andaluz de la Mujer, pp. 221-240.

HARAWAY, DONNA (1995). Ciencia, cyborgs y mujeres. La reinvención de la naturaleza, Madrid: Cátedra.

KOYAMA, EMI (2001). The Transfeminist Manifesto en DICKER, Rory y PIEPMEIER, Alison (ed.) (2003). Catching A Wave: Reclaiming Feminism for the Twenty-First Century, Boston: Northeastern University Press. Dirección: http://eminism.org/ (Última consulta: 28 de octubre de 2014).

OLD BOYS NETWORK (1997). 100 anti-theses, First Cyberfeminist International, Kassel. Dirección: http://www.obn.org/reading_room/ manifestos/html/anti.html (Última consulta: 20 de octubre de 2014).

PLANT, SADIE (1998). Ceros + unos: mujeres digitales + la nueva tecnocultura, Barcelona: Destino.

RADIO MALVA (Sin fecha). Qué es Radio Malva. En “Radio Malva”. Dirección: http://radiomalva.org/el-colectivo/ (Última consulta: 23 de octubre de 2014).

RED NOSOTRAS EN EL MUNDO (Sin fecha). Quiénes somos. En "Red Nosotras en el Mundo". Dirección: http://www.rednosotrasenelmundo. org/spip.php?page=quienes-somos (Última consulta: 23 de octubre de 2014).

RODRÍGUEZ BORGES, RODRIGO FIDEL (2006). Radio e información. Elementos para el análisis de los mensajes radiofónicos, La Laguna: Servicio de publicaciones, Universidad de La Laguna.

SCOTT, Joan W. (2011). El género: ¿Todavía una categoría útil?. Revista La Manzana de la discordia, vol. 6, número 1, Universidad del Valle, CaliColombia, pp. 95-101. Dirección: http://manzanadiscordia.univalle.edu.co/ volumenes/V6N1.html (Última consulta: 17 de octubre de 2014).

SEGARRA, MARTA (2012). Comunidades y literatura en SEGARRA, Marta (Ed.) (2012). Repensar la comunidad desde la literatura y el género, Barcelona: Icaria.

SOLLFRANK, CORNELIA (2007). La verdad sobre el ciberfeminismo. Dirección: http://www.2-red.net/habitar/tx/text_cs_c.html (Última consulta: 20 de octubre de 2014).

VALENCIA, SAYAK (2013). Transfeminismo(s) y capitalismo gore en SOLÁ, Miriam y URKO, Elena (Comp.). Transfeminismos. Epistemes, fricciones y flujos, Tafalla: Txalaparta. 
VALLES, MIGUEL S. (1997). Técnicas cualitativas de investigación social. Reflexión metodológica y práctica profesional, Madrid: Síntesis Editorial.

VAN DIJK, TEUN A. (2010). Discurso, conocimiento, poder y política. Hacia un análisis crítico epistémico del discurso. Revista de Investigación Lingüística, $n^{\circ}$ 13, pp. 167-215. Dirección: http://revistas.um.es/ril/article/view/114181 (Última consulta: 31 de octubre de 2014)

VAN DIJK, TEUN A. (2001). El análisis crítico del discurso y el pensamiento social. Athenea Digital, no 1, pp. 18-24. Dirección: http://dialnet.unirioja.es/ servlet/articulo?codigo=1226841 (Última consulta: 31 de octubre de 2014)

VAN DIJK, TEUN A. (2009). Discurso y Poder, Barcelona: Gedisa.

VNS MATRIX (1991). Cyberfeminist Manifesto for the 21st Century. Dirección: http://www.obn.org/reading_room/manifestos/html/cyberfeminist.html (Última consulta: 20 de octubre de 2014).

VNS MATRIX (1996). Bitch Mutant Manifesto. Dirección: http://www.obn. org/reading_room/manifestos/html/bitch.html (Última consulta: 20 de octubre de 2014).

WAJCMAN, JUDY (2006). El tecnofeminismo, Madrid: Cátedra.

WILDING, FAITH \& CRITICAL ART ENSEMBLE (1998). Notas sobre la condición política del ciberfeminismo. Dirección: http://www.mujeresenred.net/ spip.php?article1547 (Última consulta: 20 de octubre de 2014).

ZAFRA, REMEDIOS (2010a). Un cuarto propio conectado. (Ciber)espacio y (auto)gestión del yo, Madrid: Fórcola.

ZAFRA, REMEDIOS (2010b). A room of one's own - online - feminismo $e$ Internet desde la esfera público-privada en ZAFRA, Remedios (coord.) (2010). Xoy1 \#ensayos sobre género y ciberespacio, Madrid: Briseño, pp. 81-96. Dirección: http://xoy1.net/proyectos/ (Última consulta: 20 de octubre de 2014). 